\title{
Personality type differences between Ph.D. climate researchers and the general public: implications for effective communication
}

\author{
C. Susan Weiler • Jason K. Keller • Christina Olex
}

Received: 27 August 2009 / Accepted: 28 July 2011 /Published online: 2 September 2011

(C) The Author(s) 2011. This article is published with open access at Springerlink.com

\begin{abstract}
Effectively communicating the complexity of climate change to the public is an important goal for the climate change research community, particularly for those of us who receive public funds. The challenge of communicating the science of climate change will be reduced if climate change researchers consider the links between personality types, communication tendencies and learning preferences. Jungian personality type is one of many factors related to an individual's preferred style of taking in and processing information, i.e., preferred communication style. In this paper, we demonstrate that the Jungian personality type profile of interdisciplinary, early career climate researchers is significantly different from that of the general population in the United States. In particular, Ph.D. climate researchers tend towards Intuition and focus on theories and the "big picture", while the U.S. general population tends towards Sensing and focuses on concrete examples and experience. There are other differences as well in the way the general public as a group prefers to take in information, make decisions, and deal with the outer world, compared with the average interdisciplinary climate scientist. These differences have important implications for communication between these two groups. We suggest that climate researchers will be more effective in conveying their messages if they are aware of their own personality type and potential differences in preferred learning and communication styles between themselves and the general public (and other specific audiences), and use this knowledge to more effectively target their audience.
\end{abstract}

\section{S. Weiler $(\bowtie)$}

Office for Earth System Studies, Whitman College, Walla Walla, WA 99362, USA

e-mail: weiler@whitman.edu

\section{J. K. Keller}

School of Earth and Environmental Sciences, Chapman University, Orange, CA 92866, USA

C. Olex

The Point, 121 Jewett Street, Newton, MA 02458, USA 


\section{Introduction}

Of all the applications of the Myers-Briggs Type Indicatory personality inventory, perhaps none holds greater promise than education for assisting our efforts to deal with social change in an increasingly pluralistic world. J.K. DiTiberio 1998

As the Intergovernmental Panel on Climate Change (IPCC) embarks on its fifth assessment, it has become increasingly clear that effectively communicating climate-related information to the general public remains an ongoing challenge for the climate change research community (Moser and Dilling 2004, 2007; Marx et al. 2007; Weart 2008; Leiserowitz 2006; Ward 2008). One area that has not been fully explored within the climate research community is the relationship between psychological personality type (Myers et al. 1998) and preferred communication/learning style. More than 2 million people in the U.S. alone take the Myers-Brigg Type Indicator $\left(\mathrm{MBTI}^{\circledR}\right)$ personality test each year, and it has been translated into more than 30 languages. Despite this, Academics in general and natural scientists in particular have been slow to accept the validity of personality type theory and to recognize the value of personality type training as a tool for enhancing communication. In this paper we provide evidence that the Jungian personality type of climate scientists is different from that of the general U.S. population and suggest that we use this knowledge to enhance our ability to communicate more effectively with the general public.

Modern type theory is generally taken to date to 1921, when psychologist Carl Jung published a model with eight personality types based on research involving "normal" individuals (Jung 1971 translation). Jung's theory was further expanded by Isabel Briggs Myers (Myers 1980), who subsequently developed the Myers-Briggs Type Indicator $\left(\mathrm{MBTI}^{\circledR}\right)$, a metric for identifying the preferences of different personality types. Personality type theory today is a non-judgmental evaluation of how healthy people prefer to use their minds to take in and process information. The MBTI ${ }^{\circledR}$, and similar assessments, utilize a series of questions to assign an individual's inherent preferred type for each of four dichotomies, resulting in 16 possible personality types (Myers et al. 1998). While we all use each of the dichotomous categories to some extent, they are considered as innate psychological preferences, akin to preferences for left- or right-handedness.

As summarized in Myers et al. (1998), the E/I dichotomy distinguishes people who prefer to focus their attention on the outer world of people and activity ("Extraverts", E) from those who prefer to focus their attention on the inner world of ideas and experiences ("Introverts", I). The $\mathbf{S} / \mathbf{N}$ dichotomy identifies how people prefer to perceive the world and take in information, either by focusing on the real and tangible ("Sensing", S) or by focusing on the big picture and the relationships between ideas ("Intuition", N). The $\mathbf{T} / \mathbf{F}$ dichotomy characterizes the processes people use to make decisions. Some prefer to make decisions based on objective, logical reasoning ("Thinking", T), while others rely more on personal values and the impact of decisions on others ("Feeling", F). Finally, the J/P dichotomy identifies how individuals prefer to deal with the outer world, either through a structured and organized approach with an emphasis on coming to closure ("Judging", J), or a more flexible and spontaneous manner focusing on collecting and processing information ("Perceiving", P)

In addition to explaining a great deal of behavior, Jungian personality type plays an important role in communication style (Opt and Loffredo 2000; Dunning 2003; Hirsh et al. 2003). For example, Sensing types respond to tangible information while Intuitive types 
respond to theory. Similar differences in preferred communication style exist for each of the four dichotomies of personality type (Table 1). Given this coupling between personality type and preferred communication style, the $\mathrm{MBTI}^{\circledR}$ serves as a convenient instrument to evaluate the communication preferences of different groups. For example, this approach has been used to demonstrate a potential for miscommunication between medical doctors and their patients (Clack et al. 2004).

Here, we show that the personality type profile of 209 interdisciplinary, early career $\mathrm{Ph}$.D. researchers engaged in work related to climate change is significantly different from that of the general population of the United States. Given that personality type affects an individual's preferred way of presenting and receiving information, these differences have important implications for climate change scientists to consider when communicating to a more general audience. While it is virtually impossible to know the personality type of every member of a large audience, the extensive data that have been collected on the type preferences of the U.S. general public provides climate scientists with a unique opportunity to use knowledge of type preferences when speaking to this group. We encourage climate scientists to learn their own personality types and to consider potential differences in personality types, and communication styles, between themselves and any audience, whether it is an individual or group.

Table 1 Communication tendencies for different MBTI ${ }^{\circledR}$ personality types. Adapted from Dunning (2003) and Myers et al. (1998)

\section{Extraversion - E Introversion - I}

- Think out loud in discussions, talk more than listen - Process information internally, listen more than talk

- Share ideas immediately

\section{Sensing - S}

- Focus on experience

- Share ideas after careful reflection

- Build carefully and logically towards conclusions

- Want details

- Anchored in the present, relate to the past

- Prefer step-by-step information or instructions

- Ask "what" and "how" questions

- Look for facts

- Prefer practical, plain language to symbols, metapors, theories or abstractions

\section{Thinking - T}

- Present information using cause-and-effect reasoning

- Analytical

- Need to know "why"

\section{Judging - J}

- Prefer to make decisions quickly, come to closure and move on

- Uncomfortable with free-flowing discussions

- Prefer focused discussion and options

- Focus on theories

- Follow hunches to reach conclusions

- Want big picture, become bored or impatient with details

- Oriented towards the future

- Talk in general terms

- Ask "why" questions

- Look for patterns and possibilities

- Use metaphors, analogies and other symbolic language

\section{Feeling - F}

- Use personal situations, stories and examples to communicate

- Empathetic

- Connect with people

\section{Perceiving - $\mathbf{P}$}

- Prefer to stay open to new information and last-minute options

- Feel confined by detailed plans and final decisions

- Prefer open discussion to explore linkages between topics 


\section{Methods}

\subsection{Ph.D. climate researcher population}

Personality types of interdisciplinary, Ph.D. climate change researchers were collected as part of six symposia held between 2002 and 2008. Five of these symposia were associated with the Dissertations Initiative for the Advancement of Climate Change Research (DISCCRS; http:// disccrs.org) and one was a special symposium for scholars conducting polar research during the International Polar Year (IPY, 2007-2008), the New Generation of Polar Researchers (NGPR; http://www.apecs.is/workshops/ngpr). The aim of all six symposia was to foster interdisciplinary work by connecting new researchers who are striving to create and integrate knowledge across multiple disciplines. Each symposium brought together 35-40 scholars who had completed their Ph.D.s within 24 months of the application deadline in any subject relevant to the study of climate change and its impacts, or who were conducting research during the IPY. Participants were competitively selected based on scholarly excellence and demonstrated commitment to interdisciplinary research.

Prior to arriving at each symposium, the invited participants were invited to take an on-line version of the Jungian type personality assessment (described below) and asked to submit the results to the symposium organizer. Individual scores were held confidentially, but permission was granted to use the collective, anonymous scores as part of a training exercise on personality type in the context of communication and team dynamics, and for future publication.

In all, 209 of the 210 attending symposium scholars submitted their 4-letter personality type. Of the 209, 100 (48\%) were male and 109 (52\%) female (Table 2), Most (81\%) were American citizens, U.S. residents, and/or completed their Ph.D. degree in the U.S. Primary fields of Ph.D. research spanned the physical (51\%), biological (24\%) and social sciences (25\%). All participants were selected because they had interests beyond their primary field of expertise, and many worked or collaborated across disciplines even at their early career stage.

\subsection{Personality type assessment}

The most common and well-studied Jungian type personality assessment is the MBTI $^{\circledR}$ Form M (Myers et al. 1998). This assessment is composed of 93 questions and uses a forced choice answer modality (i.e., would you prefer A or B?). Ultimately, this instrument provides a tally of choices that results in preferences for each of the 4 dichotomous scales of type (Myers et al. 1998). For logistical reasons, we utilized the Jung Typology Test ${ }^{\text {TM }}$ (JTT ${ }^{\text {TM}}$ ), a free online typology assessment (Humanmetrics 2009). This assessment is comprised of 72 questions each offering a "Yes" or "No" answer choice, and once again uses a forced choice methodology. The type results from both the MBTI ${ }^{\circledR}$ and the JTT $^{\mathrm{TM}}$ assessments are indicators, meaning that they can point a person in the right direction to their Jungian type. Only through 'self-reporting' - checking in with participants - can type actually be verified. The MBTI ${ }^{\circledR}$ Form M typically shows $>90 \%$ agreement between assessment results and 'self-reporting' on at least 3 of the 4 dichotomies (Myers et al. 1998), and we expect similar patterns among our participants. It should be noted that the MBTI $^{\circledR}$ has a long history of discussion focusing on the reliability and validity of the instrument's scores (e.g., Carlyn 1977; Carlson 1985; Capraro and Capraro 2002; Salter et al. 2005), and some authors have questioned the utility of the instrument (e.g., Pittenger 1993). It is beyond the scope of this paper to contribute to this discussion, and our focus on 
Table 2 Personality type preferences for the 209 recent, interdisciplinary Ph.D. graduates who participated in the DISCCRS and NGPR symposia. Data are organized by self-identified primary research discipline and gender

\begin{tabular}{|c|c|c|c|c|c|c|c|c|c|}
\hline $\begin{array}{l}\text { Primary } \\
\text { Research } \\
\text { Discipline }\end{array}$ & Number (\%) & $\mathbf{E}$ & I & $\mathbf{S}$ & $\mathbf{N}$ & $\mathbf{T}$ & $\mathbf{F}$ & $\mathbf{P}$ & $\mathbf{J}$ \\
\hline $\begin{array}{r}\text { Biological } \\
\text { Sciences }\end{array}$ & $50(24 \%)$ & $26(52 \%)$ & $24(48 \%)$ & $9(18 \%)$ & $41(82 \%)$ & $22(44 \%)$ & $28(56 \%)$ & $7(14 \%)$ & $43(86 \%)$ \\
\hline $\begin{array}{l}\text { Physical } \\
\text { Sciences }\end{array}$ & $106(51 \%)$ & $56(53 \%)$ & $50(47 \%)$ & $20(19 \%)$ & $86(81 \%)$ & $52(49 \%)$ & $54(51 \%)$ & $29(27 \%)$ & $77(73 \%)$ \\
\hline $\begin{array}{l}\text { Social } \\
\text { Sciences }\end{array}$ & $53(25 \%)$ & $31(58 \%)$ & $22(42 \%)$ & $8(15 \%)$ & $45(85 \%)$ & $28(53 \%)$ & $25(47 \%)$ & $14(26 \%)$ & $39(74 \%)$ \\
\hline Gender & Number (\%) & $\mathbf{E}$ & I & $\mathbf{S}$ & $\mathbf{N}$ & $\mathbf{T}$ & $\mathbf{F}$ & $\mathbf{P}$ & $\mathbf{J}$ \\
\hline Male & $100(48 \%)$ & $47(47 \%)$ & $53(53 \%)$ & $15(15 \%)$ & $85(85 \%)$ & $59(59 \%)$ & $41(41 \%)$ & $29(29 \%)$ & $71(71 \%)$ \\
\hline Female & $109(52 \%)$ & $66(61 \%)$ & $43(39 \%)$ & $22(20 \%)$ & $87(80 \%)$ & $43(39 \%)$ & $66(61 \%)$ & $21(19 \%)$ & $88(81 \%)$ \\
\hline
\end{tabular}

Jungian personality type as a metric of communication style remains a common interpretation of the MBTI ${ }^{\circledR}$ and similar instruments (Myers et al. 1998; Dunning 2003; Clack et al. 2004).

\subsection{Comparisons with a representative sample of the U.S. population}

To explore the potential for different preferred communication styles between climate scholars from this study and the U.S. general population, the personality-type profiles of the 209 climate scholars from this study using the JTT ${ }^{\mathrm{TM}}$ were compared to the personality preferences of the Myers et al. (1998) U.S. National Representative Sample, which they scored using the MBTI ${ }^{\circledR}$ Form M. The U.S. National Representative Sample $(n=3,009)$ is a modified version of data in their National Sample $(n=3,036)$ collected using a random stratified design. The National Representative Sample was modified to approximate the U.S. population in terms of gender and ethnicity by applying weights to categories that were undersampled compared with the 1996 U.S. census data. We compared our data with theirs by applying a chi-squared test (SPSS 2006). We restricted our statistical analysis to the major dimensions of each dichotomy (i.e., the E/I, $\mathrm{S} / \mathrm{N}, \mathrm{T} / \mathrm{F}$ and $\mathrm{J} / \mathrm{P}$ dichotomies). We acknowledge that the JTT ${ }^{\mathrm{TM}}$ is not the standard metric for personality type assessment; however, our results were generally consistent across symposia and across primary research area (Table 2). Similar patterns were also observed in a separate series of symposia focusing on the aquatic sciences (Dissertations Initiative for the Advancement of Limnology and Oceanography Symposia; Weiler, unpublished data) where the MBTI ${ }^{\circledR}$ Form M was used. Thus, while comparisons of results obtained from two different assessments should be viewed with caution, we are confident that the general patterns revealed in our analyses are robust.

\section{Results}

The prevailing personality types of early career climate scientist were different from the National Representative Sample in the United States on 3 of the 4 dichotomies analyzed (Fig. 1): S/N, T/F and J/P. The proportions of Extraverts (54\%) and Introverts (46\%) among 


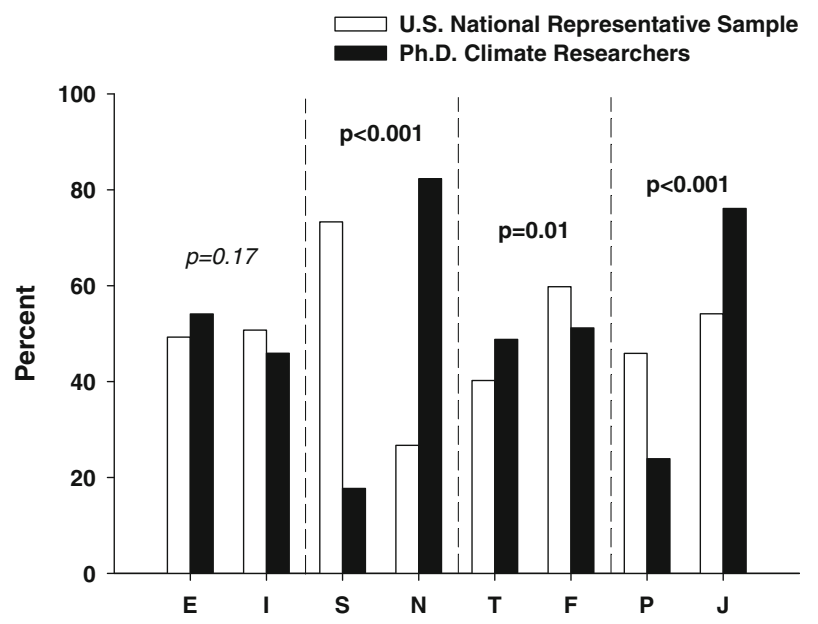

Fig. 1 Comparison of personality preferences of the National Representative Sample in the United States (open bars, $N=3009$, Myers et al. 1998) and interdisciplinary, early career Ph.D. climate change researchers (closed bars, $N=209$ ). For each personality type dichotomy, significant differences $(p<0.05)$ based on chisquare tests are indicated in bold. Data from the National Representative Sample show 49\% and $51 \%$ for the $\mathrm{E} / \mathrm{I}$ dichotomy; $73 \%$ and $27 \%$ for the $\mathrm{S} / \mathrm{N}$ dichotomy; $40 \%$ and $60 \%$ for the $\mathrm{T} / \mathrm{F}$ dichotomy; and $54 \%$ and $46 \%$ for the $\mathrm{J} / \mathrm{P}$ dichotomy. In contrast, the climate change researchers show $54 \%$ and $46 \%$ for the $\mathrm{E} / \mathrm{I}$ dichotomy; $82 \%$ and $18 \%$ for the $\mathrm{S} / \mathrm{N}$ dichotomy; $49 \%$ and $51 \%$ for the T/F dichotomy; and $76 \%$ and $24 \%$ for the $\mathrm{J} / \mathrm{P}$ dichotomy

symposia participants were not significantly different from the preferences of the U.S. general population, which was $49 \%$ Extraverted and $51 \%$ Introverted $(p=0.17)$. Climate researchers showed a dramatic preference for Intuition $(82 \%)$ over Sensing $(18 \%)$, and this was significantly different $(p<0.001)$ from the National Representative Sample in the United States, which preferred Sensing (73\%) over Intuition $(27 \%)$. There was an even split between the preference for Thinking (49\%) and Feeling (51\%) among the Ph.D. climate researchers, and this pattern reflects a difference from the general population, which was $40 \%$ Thinking and $60 \%$ Feelng $(p=0.01)$. Finally, symposia scholars showed a stronger preference for Judging (76\%) than for Perceiving $(24 \%)$, and this pattern was significantly different $(p<0.001)$ from the National Representative Sample, which was 54\% Judging and 46\% Perceiving. Gender may account for some of the type differences between the two groups, but the gender ratio in our sample $(52 \%$ female, $48 \%$ male $)$ is quite similar to the U.S. National Representative sample ( $51 \%$ female and $49 \%$ male). The only characteristic with a gender difference in the National Representative Sample is the T/F dichotomy, with a split of $24 \% / 76 \%$ among female respondents and $56 \% / 44 \%$ among males. In comparison, the $\mathrm{T} / \mathrm{F}$ split for our sample of climate researchers was 39\%/61\% among females and $59 \% / 41 \%$ among males.

When compared with the U.S. National Representative Sample, a number of personality types were particularly well-represented among interdisciplinary Ph.D. climate researchers (Fig. 2). Over 20\% of the participants in the climate change symposia preferred the ENFJ personality type, compared with just 3\% of the general population in the United States. The INTJ (15\%), ENTJ (12\%) and INFJ $(12 \%)$ personality types were also much more common among symposia participants than in the general population of the United States (Fig. 2). 


\begin{tabular}{|c|c|c|c|}
\hline $\begin{array}{c}\text { ISTJ } \\
\otimes \otimes \otimes \otimes \otimes \otimes \bigcirc \\
\bigcirc \bigcirc \bigcirc \bigcirc \bigcirc\end{array}$ & $\begin{array}{c}\text { ISFJ } \\
\otimes \otimes \bigcirc \bigcirc \bigcirc \bigcirc \bigcirc \\
\bigcirc \bigcirc 0000 \bigcirc\end{array}$ & $\begin{array}{c}\text { INFJ } \\
\otimes \otimes \bullet \bullet \bullet \bullet \bullet ~ \\
\bullet \bullet \bullet \bullet \bullet \bullet ~\end{array}$ & 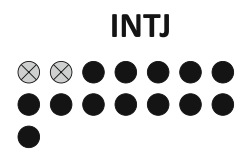 \\
\hline $\begin{array}{c}\text { ISTP } \\
\bigcirc \bigcirc \bigcirc \bigcirc \bigcirc\end{array}$ & $\begin{array}{c}\text { ISFP } \\
\otimes \bigcirc \bigcirc \bigcirc \bigcirc \bigcirc \bigcirc \\
\bigcirc \bigcirc\end{array}$ & $\otimes \otimes \otimes \otimes$ & $\otimes \otimes \otimes \bullet \bullet$ \\
\hline $\begin{array}{c}\text { ESTP } \\
000 \bigcirc\end{array}$ & $\begin{array}{l}\text { ESFP } \\
\otimes \bigcirc \bigcirc \bigcirc \bigcirc \bigcirc \bigcirc \\
\bigcirc \bigcirc\end{array}$ & $\begin{array}{c}\text { ENFP } \\
\otimes \otimes \otimes \otimes \otimes \otimes \bigcirc \\
\bigcirc\end{array}$ & 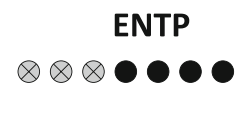 \\
\hline $\begin{array}{c}\text { ESTJ } \\
\otimes \otimes \bigcirc \bigcirc \bigcirc \bigcirc \bigcirc \\
\bigcirc \bigcirc\end{array}$ & $\begin{array}{c}\text { ESFJ } \\
\otimes \otimes \otimes \otimes \bigcirc \bigcirc \bigcirc \\
\bigcirc \bigcirc \bigcirc \bigcirc \bigcirc\end{array}$ & $\begin{array}{r}\text { ENFJ } \\
\otimes \otimes \otimes 0000 \\
0000000 \\
0000000\end{array}$ & $\begin{array}{c}\text { ENTJ } \\
\otimes \otimes \bullet \bullet \bullet \bullet \bullet ~ \\
\bullet \bullet \bullet \bullet \bullet \bullet\end{array}$ \\
\hline
\end{tabular}

U.S. National Sample $n=3,000 \otimes$ Both (overlap)

- Climate Researchers $n=209$

Fig. 2 Comparison of personality preferences of the National Representative Sample in the United States (white circles, $N=3009$, Myers et al. 1998) and of interdisciplinary, early career Ph.D. climate change researchers (black circles, $N=209$ ). Each circle represents one percent of the populations sampled. Data were rounded to the nearest whole percentage, so numbers may not add up to $100 \%$. Circles are superimposed for comparison, with gray circles with " $x$ " inside representing overlap between the two populations

\section{Discussion}

Our results demonstrate that the dominant personality types for Ph.D. climate change researchers are fundamentally different from those found in the U.S. population. This suggests that there is a strong potential for inherent challenges in communication between these two groups. As the climate change community continues to move forward with effective communication and education, it is important to keep in mind that it isn't just "what we say" but, "how we say it".

Scientists in general are well trained and excellent communicators when it comes to exchanges with specialists in their own discipline. They are less well trained at communicating across disciplinary boundaries, and have even more difficulties in communicating with a non-specialist audience. Part of the challenge is to avoid jargon and to simplify complex data so that it can be understood by a non-specialist. However, our personality-type data suggest that even better results could be obtained by taking one's own personality type, and the audience's known, or likely, type into consideration when approaching communication..

The "type" of one's audience is usually much harder to ascertain than one's own. Given what is known about the general population from the U.S. National Representative Sample, however, there is at least the opportunity to make an educated guess about the composition of a general-public audience. Given that the vast majority of interdisciplinary climate 
scientists are likely to prefer Intuition and a general-public audience is likely to be predominately composed individuals who prefer Sensing (Fig. 1), understanding the preferred communication styles of this dichotomy is likely to be particularly important for climate researchers to consider when communicating with the general population.

The MBTI ${ }^{\circledR}$ Type Tables for Occupations provide data on the frequency of types in a variety of occupations (Schaubhut and Thompson 2008). For example, Schaubhut and Thompson (2008) identify ENFP as the most frequent personality type for college or university faculty members $(12 \%)$. While most of the participants in the climate change symposia were still in post-doctoral positions, the majority intended to pursue academic careers. Interestingly, in contrast to the data reported by Schaubhut and Thompson (2008), ENFJ was the most frequent type for the Ph.D. climate researchers attending the symposia, with ENFP ranking as only the fifth most frequent personality type (Fig. 2). Similarly, only $7 \%$ of symposia participants preferred the ISTJ personality type which is the most frequent personality type for a variety of scientific occupations including: biochemists, biologists, chemists, economists, geoscientists, microbiologists, plant scientists and statisticians (Schaubhut and Thompson 2008).

Symposia participants exhibited a strong preference (82\%) for taking in information through Intuition (Fig. 1). Overall, $62 \%$ of the college or university faculty in Schaubhut and Thompson (2008) indicated a preference for Intuition, as did the majority of biochemists, biologists, chemists, economists, geoscientists, microbiologist, plant scientists and statisticians. However, none of these career types were as extreme in their preferences for Intuition as the climate researchers in our study. It may well be that this tendency towards Intuition is a by-product of our selection for interdisciplinary scholars over specialists in specific disciplines.

These apparent discrepancies highlight the fact that the personality of two individual climate change scientist may be completely different (as might the personality types of any two members of any population). Thus, while we make suggestions on how the 'typical' climate change researcher might more effectively communicate with the 'typical' member of the general population, these recommendations will not fit every situation. We therefore encourage all scientists to consider their personality type, and preferred communication style, when developing strategies for effectively communicating with the general public and with other audiences. Efforts to include a 'balanced approach' to reach all preferred styles, not just those with which an individual researcher is most naturally comfortable, will increase chances of effective communication with a mixed audience. This is especially important now that more research is done concerning perspectives of the general public on the topic of climate change (Maibach et al. 2009).

The preference for Intuition by early career climate scientists suggests that this group is likely to be more oriented towards future climate impacts than members of the general public, who generally prefer Sensing over Intuition (Fig. 1). For Sensors, the current situation is more relevant and more easily appreciated, and past experience and concrete facts are more trusted than future possibilities. Thus, climate impacts beyond the present or readily foreseeable future may lack relevance among the general public. This is reinforced by Kastens et al. (2009) who suggest that in contrast to the general population, geoscientists are characterized by an ability to think about past and future geological events in addition to the present situation. Scientists who prefer Intuition can help bridge this potential communication divide by starting with the concrete and short term and building towards the big picture without any leaps in cause and effect. By beginning with the current state and moving on to how the current state is changing, using a step-by-step approach to how these changes will impact the future, Intuitive researchers can facilitate an understanding of 
these connections with a Sensing audience. When communicating with Sensors, it is also important to focus on concrete near-home examples. While the plight of polar bears may be of great concern to Intuitives, Sensors are likely to be motivated more by documented temperature or seasonal changes in their local areas. In other words, with this audience, you may think globally, but you should speak locally.

Our sample of climate researchers was equally split between Feeling and Thinking preferences, a significant over-representation of Thinkers compared to the general population (Fig. 1). Our results suggest that the climate-change research community may more effectively communicate with the general public by including the personal and local impacts of climate change in addition to more analytical results. This is also in line with the preferences of Sensors. The personal/local "Feeling" communication style may come naturally to roughly half of the climate research community, but the other half will need to learn and practice it more to be as naturally effective as their counterparts.

Compared to the United States population, Ph.D. climate scientists also exhibited a strong preference for Judging on the final dichotomy (Fig. 1). This suggests that on average, climate change researchers will prefer to reach a decision or come to closure and 'move on' to the next step more quickly than the general population. The general population, with a higher proportion of Perceivers, is more likely to see room for doubt, or want to take more time to explore possible alternatives, especially when outcomes are not likely to be positive. When presenting climate change to the general public, it is important for researchers to confirm what information is still unknown and what areas are still being studied. In this regard, Ward (2008) suggested that "scientists should talk with reporters during the research stage, and not simply when their findings are published in a journal. Sometimes the process of research is what can engage an audience." As others have pointed out, balancing simplified statements of certainty with more complex statements that reflect the full range of uncertainties associated with climate change is an inherent challenge when communicating with the general public (Moser and Dilling 2004), and one that must be addressed.

The inherent differences in the preferred communication styles of early career Ph.D. climate researchers and the general public (Fig. 1) are likely to exacerbate the challenge of effectively communicating climate change if they are not addressed. Knowledge of personality type provides a powerful tool that can be used to improve communication, and lead to greater public understanding of climate change and its impacts. As preferred communication style varies considerably within the climate change research community (Fig. 2), it is impossible to suggest universal strategies to improve communication. However, we suggest that by being aware of one's own personality type and communication style, an individual researcher can better consider how to communicate with audiences made up of a broad range of personality types that are likely to be different from his or her own. Improved understanding of personality type can help us communicate better with our students, colleagues and, perhaps most importantly, will facilitate communicating important climate change information with the general public.

Acknowledgements Work on this project was funded through National Science Foundation Grants EAR 0435728, EAR 0105201, SES 0932916 and ARC-0632324 to Whitman College. Weiler was also supported on this project through her current position at the National Science Foundation. Any opinions, finding, and conclusions or recommendations expressed by her through this project do not necessarily reflect the views of the National Science Foundation. We thank all the symposia scholars for their willingness to provide us with their type indicators and their lively discussions during the symposia on the relevance of personality type in their individual and collective professional development and interactions beyond the ivory tower. Comments from Kristin Kuntz-Duriseti and three anonymous reviewers greatly improved this manuscript. 
Open Access This article is distributed under the terms of the Creative Commons Attribution Noncommercial License which permits any noncommercial use, distribution, and reproduction in any medium, provided the original author(s) and source are credited.

\section{References}

Capraro RM, Capraro MM (2002) Myers-Briggs Type Indicator score reliability across studies: a meta-analytic reliability generalization study. Educ Psychol Meas 62:590-602

Carlson JG (1985) Recent assessments of the Myers-Briggs Type Indicator. J Personal Assess 49:356-365

Carlyn M (1977) An assessment of the Myers-Briggs Type Indicator. J Personal Assess 41:461-473

Clack GB, Allen J, Cooper D et al (2004) Personality differences between doctors and their patients: implications for the teaching of communication skills. Medical Education 38:177-186

DiTiberio JK (1998) P. 253 in, Myers IB, McCaulley MH, Quenk NL et al. MBTI ${ }^{\circledR}$ Manual: A Guide to the Development of the Myers-Briggs Type Indicator ${ }^{\circledR}$. Consulting Psychologists Press, Inc., Palo Alto, CA

Dunning D (2003) Introduction to Type ${ }^{\circledR}$ and Communication. Consulting Psychologists Press, Inc., Palo Alto

Hirsh E, Hirsh KW, Krebs Hirsh S (2003) Introduction to type and teams. Consulting Psychologists Press, Inc., Palo Alto

Humanmetrics (2009) Jung Typology Test ${ }^{\mathrm{TM}}$. http://www.humanmetrics.com/cgi-win/JTypes2.asp. July 23, 2009

Jung CG (1971) Psychological types. Princeton University Press, Princeton

Kastens KA, Manduca CA, Cervato C et al (2009) How geoscientists think and learn. Eos Transactions of the American Geophysical Union 31:265-272

Leiserowitz A (2006) Climate change risk perception and policy preferences: the role of affect, imagery, and values. Clim Chang 77:45-72

Maibach E, Roser-Renouf C, Leiserowitz A (2009) Global warming's six Americas 2009: an audience segmentation analysis. George Mason University Center for Climate Change Communication Washington, DC

Marx S, Weber E, Orlove B, Leiserowitz A, Krantz D, Roncoli C, Phillips J (2007) Communication and mental processes: Experiential and analytic processing of uncertain climate information. Glob Environ Chang 17(1):47-58

Moser SC, Dilling L (2004) Making climate hot: communicating the urgency and challenge of global climate change. Environment 46:32-46

Moser S, Dilling L (eds) (2007). Creating a climate for change: Communicating climate change and facilitating social change. Cambridge University Press

Myers IB (1980) Gifts differing. Consulting Psychologist Press, Inc., Palo Alto

Myers IB, McCaulley MH, Quenk NL et al (1998) MBTI ${ }^{\circledR}$ manual: a guide to the development of the Myers-Briggs type indicator ${ }^{\circledR}$. Consulting Psychologists Press, Inc., Palo Alto

Opt SK, Loffredo DA (2000) Rethinking communication apprehension: a Myers-Briggs perspective. J Psychol 134:556-570

Pittenger DJ (1993) The utility of the Myers-Briggs type indicator. Rev Educ Res 63:467-488

Salter DW, Forney DS, Evans NJ (2005) Two approaches to examining the stability of Myers-Briggs type indicator scores. Meas Eval Couns Dev 37:208-219

Schaubhut NA, Thompson RC (2008) MBTI $^{\circledR}$ type tables for occupations. Consulting Psychologists Press, Inc., Palo Alto

SPSS (2006) SPSS 15.0 for windows. SPSS, Inc., Chicago, IL

Ward B (2008) Communicating on climate change: an essential resource for journalists, scientists, and educators. Metcalf Institute for Marine \& Environmental Reporting, Narragansett

Weart SR (2008) The Discovery of Global Warming. 2d edition. Harvard University Press. see also http:// www.aip.org/history/climate/index.htm 